\title{
Stability of Residual Thiosulfate in Processed Microfilm
}

\author{
C. I. Pope
}

(August 21, 1962)

\begin{abstract}
The concentration of residual thiosulfate (hypo) in processed microfilm and its variation with storage humidity were measured. The initial thiosulfate concentration varied linearly with the image density up to a density of about 2. The rate of decomposition of the thiosulfate increased as the relative humidity increased. The concentration of thiosulfate in a silver-free area remained constant for nine months in film stored at 14-percent relative humidity but began to decrease within two weeks at 88 -percent relative humidity. The residual thiosulfate in processed microfilm reacted with the silver in the image to form silver sulfide and the amount of sulfiding during aging at 88-percent relative humidity was measured. The residual thiosulfate concentration in microfilm was found to vary linearly with the silver concentration in the fixing bath. Potassium bromide, potassium iodide, and sodium chloride reacted with the residual silver thiosulfate complex making the thiosulfate soluble. Potassium bromide and iodide effected the complete elimination of thiosulfate.
\end{abstract}

\section{Introduction}

The use of microfilm for record purposes has increased rapidly during the past three decades and many microfilm records are intended for archival use. In the usual silver halide photographic process the image is fixed in a solution of sodium or ammonium thiosulfate and then the film is washed to remove the thiosulfate. If, due to inadequate washing, the residual thiosulfate concentration is excessive, the image may be damaged or destroyed since the thiosulfate reacts with the image silver to form silver sulfide and this reaction takes place rapidly at high relative humidities.

It is known that the thiosulfate concentration in freshly processed microfilm varies with the image density and that the thiosulfate decomposes during storage $[1,2,5]{ }^{1}$ Data were needed on the decomposition of residual thiosulfate to determine the conditions under which the analysis for the residual thiosulfate could be expected to assess the potential damage to the image on storage.

The relationship of the residual thiosulfate content to the image density on freshly processed microfilm was measured for a wide range of densities. The decrease in the thiosulfate content and the amount of image silver sulfided during aging were measured. The effect of the nature of the fixing bath on the retention of thiosulfate during washing and the role of halide salts in removing thiosulfate from microfilm after fixation were investigated.

\footnotetext{
1 Figures in brackets indicate the literature references at the end of this paper.
}

\section{Preparation of Samples}

Samples of $35 \mathrm{~mm}$ microfilm were cut in 10-in. lengths and exposed in an intensity scale sensitometer. The processing procedures were similar to those described in a previous paper [6]. The samples were developed $3 \mathrm{~min}$, treated $30 \mathrm{sec}$ in a stop bath, and fixed $6 \mathrm{~min}$ (3 $\mathrm{min}$ in each of two fresh baths). The processing was carried on at room temperature $\left(22\right.$ to $28{ }^{\circ} \mathrm{C}$ ) employing the solutions listed in the appendix, section 9.1. About 2 liters of fresh solution were used in each processing operation employing nominal 8 by 10 -in. enameledmetal trays. Not more than eight samples were processed or treated at one time. The samples were continuously agitated by hand during processing. The samples were washed in a rapidly flowing stream of tap water at a constant temperature and for the required washing time to obtain the desired residual thiosulfate concentrations in processed microfilm or to measure the decrease of the thiosulfate concentration for different washing times. During the first minute of washing the tray was emptied three times to facilitate the removal of the fixing solution on the surface of the samples. At the end of the washing period the samples were taken up by one end, shaken to remove the surface water, and placed, emulsion side up, on clean white blotting paper to dry.

The samples had one unexposed area and six areas with various exposures, the area of each step being $15 / 16$ in. by $1 \frac{1 / 4}{4}$ in. The exposure was controlled to obtain a density of approximately 0.3 in the area of least exposure and 4 to 4.5 in the area of greatest. 
exposure. The transmission density was measured with a densitometer calibrated against a step tablet measured by the American Standards Association method [3]. The density of the base and fog, measured on the unexposed area, was subtracted from the other density readings. In each run, several microfilm samples were given the same exposure in the sensitometer. Transmission density measurements were made on one step tablet of each kind and the others were used for the residual thiosulfate or sulfiding determinations. One square inch of film was cut from each step for the thiosulfate determination. The image densities from the same runs showed a variation of 0.00 to 0.03 in the low densities and 0.00 to 0.05 in the high. These variations in the image density in the same run were not large enough to cause a measurable difference in the thiosulfate and sulfiding determinations. The original thiosulfate determination was made within an hour after processing. The thiosulfate contents were generally the same for the same steps in the tablets in each run but there was an occasional variation of $1 \mu \mathrm{g} / \mathrm{in}^{2}$ in the low image densities and 1 to $3 \mu \mathrm{g}$ in the high image densities when the thiosulfate concentrations were low but a variation of 2 to $5 \mu \mathrm{g}$ in all image densities when the thiosulfate concentration was 60 to $70 \mu \mathrm{g}$.

The thiosulfate content in the processed microfilm was determined by the American Standards Association method [4] except that more standard solutions were used and the test samples and standards were allowed to stand $25 \mathrm{~min}$ instead of $15 \mathrm{~min}$ before examination. The turbidity or opalescence of the solutions was compared with the prepared standards visually. The test is very sensitive, being capabl of detecting one part of thiosulfate in one million. Standard samples for comparison were prepared by adding $2,5,7,10,15,20,25,30,35,40,45,50,55$, $60,65,70$, and $75 \mu \mathrm{g}$ of sodium thiosulfate $\left(\mathrm{Na}_{2} \mathrm{~S}_{2} \mathrm{O}_{3}\right)$ to the $10-\mathrm{ml}$ mercuric chloride-potassium bromide test solution. The thiosulfate concentrations are expressed in terms of anhydrous sodium thiosulfate $\left(\mathrm{Na}_{2} \mathrm{~S}_{2} \mathrm{O}_{3}\right)$ in micrograms per square inch $\left(\mu \mathrm{g} / \mathrm{in} .{ }^{2}\right)$.

\section{Relationship of the Residual Thiosulfate Concentration to the Image Density}

Step tablets of microfilm were washed until the unexposed step gave a negative test for thiosulfate and the step with the lowest image density, a positive test. This was accomplished by washing the tablets, after fixation, for $3 \mathrm{~min}$ in a rapidly flowing stream of tap water at $25^{\circ} \mathrm{C}$.

Figure 1 is a photograph of seven vials showing the turbidities formed in the mercuric chloride-potassium bromide test solution by the residual thiosulfate in one square inch of film taken from each of the seven steps of a typical step tablet. Viewing from left to right, the image densities of the samples ranged from 0.00 to 4.13 and their respective thiosulfate concentrations from 0 to $10 \mu \mathrm{g} / \mathrm{in}^{2}{ }^{2}$ Though the precipitate is hardly perceptible in the photograph of the second vial, it was clearly visible during the test. A Coleman nephelometer was obtained and these experiments were repeated to compare the photoelectric method with the visual method in determining the relationship of the residual thiosulfate concentration to the image density.

The thiosulfate concentrations are plotted against the image densities in figure 2. One curve is typical for determination of the thiosulfate by the visual method and the other for the photoelectric method. The results from the nephelometer were higher in the high image densities. As shown in figure 2, the thiosulfate concentration varied practically linearly with image density up to a density of about 2 but tended to level off at the high image densities. Since the concentration of the residual thiosulfate is probably related to the amount of surface of the image silver this suggests that the surface of the silver in the high image densities does not increase proportionally with the increase in optical density. Scott [5] had previously reported that the residual thiosulfate in microfilm was roughly proportional to the image density. Thus, if the test for hypo concentration were made in a clear area, it would be possible to find no more than $5 \mu \mathrm{g}$ of residual thiosulfate

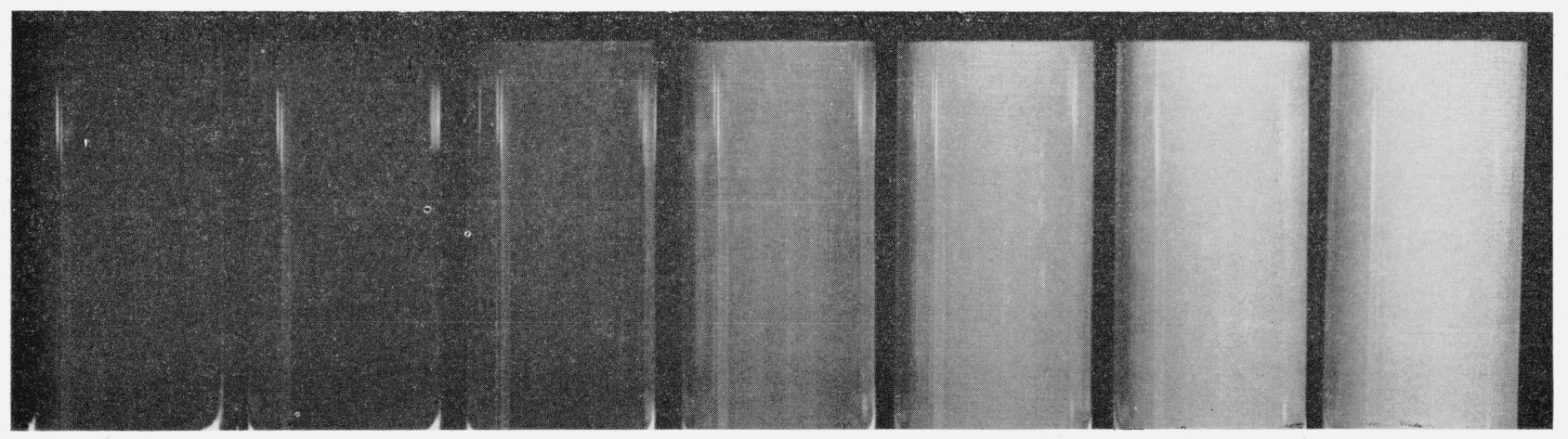

FIGURE 1. Photograph showing the turbidity of the precipitate formed by the residual thiosulfate in the thiosulfate test solution, for different image densities.

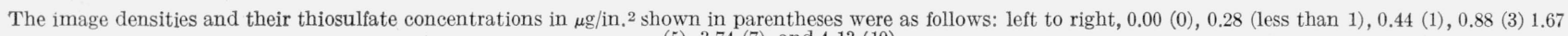
$(5), 3.74(7)$, and $4.13(10)$. 


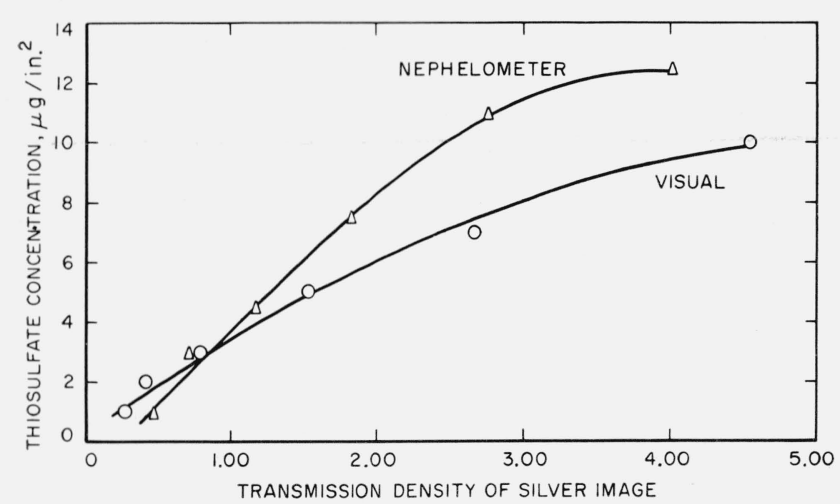

Figure 2. Residual thiosulfate concentration versus transmission (image) density in processed microfilms $A$ and $B$ when the washing is stopped as close as possible to the point where the clear area (zero image density) just ceases to give a positive test for thiosulfate.

per square inch as required by the American Standard specification for permanent record film [2] but, if the test were made in an area of high image density, well over that amount would be found.

The thiosulfate concentration during washing is shown in figure 3 for one microfilm for different image densities. Four step tablets were given the same exposure, developed and fixed together, and one step tablet was removed from the washing tray at $5,10,20$, and $60-\mathrm{min}$ intervals. It was found that the thiosulfate concentration varied nearly linearly with the image density for each washing time.

One kind of microfilm had different washing characteristics than the four other microfilms investigated. The thiosulfate was almost completely removed by washing for $10 \mathrm{~min}$, only $2 \mu \mathrm{g}$ of thiosulfate per square inch remaining in the high image densities. The amount of image silver sulfided in

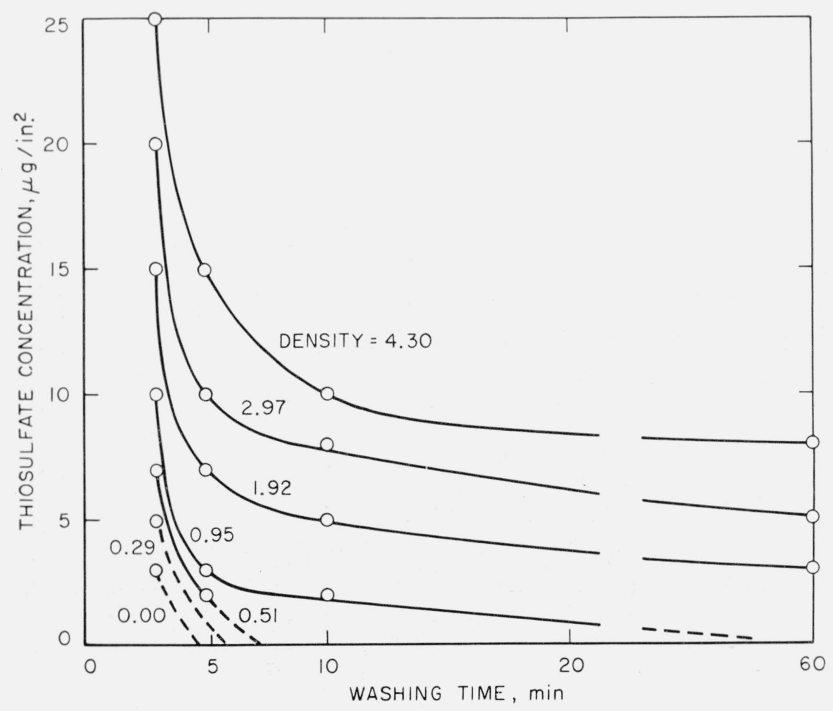

FIGURE 3. Decrease in thiosulfate concentration during washing at $25{ }^{\circ} \mathrm{C}$, for different image densities, for one microfilm. The image densities are noted on the curves. this microfilm during fixation [6] was much less than in the other films. This suggests that there is some relationship between the sulfiding of the silver image during fixing and the retention of the thiosulfate during washing. When the other four microfilms were fixed in a bath containing $1 \mathrm{~g}$ of potassium iodide per liter, only $2 \mu \mathrm{g}$ of thiosulfate per square inch remained in the high image densities after a 5-min wash and the sulfiding of the image silver during fixation was much less than normal.

\section{Effect of Humidity on the Stability of Residual Thiosulfate}

Samples of microfilm were suspended on hooks above saturated salt solutions in sealed glass jars. Saturated solutions of the following salts were used to obtain the desired relative humidities: lithium chloride, $\mathrm{LiCl}_{2} \cdot \mathrm{H}_{2} \mathrm{O}$, for 14-percent relative humidity; sodium dichromate, $\mathrm{Na}_{2} \mathrm{Cr}_{2} \mathrm{O}_{7} \cdot 2 \mathrm{H}_{2} \mathrm{O}$, for 53-percent; and barium chloride, $\mathrm{BaCl}_{2} \cdot 2 \mathrm{H}_{2} \mathrm{O}$, for 88 -percent. Sodium dichromate has been widely used to maintain the desired humidity in film storage cabinets. The saturated salt solutions were stored at room temperature ranging from 20 to $28{ }^{\circ} \mathrm{C}$. It is recognized that changes in temperature cause slight changes in the relative humidities if, as in this case, the air is not stirred, but for the present study the relative humidities were taken to be 14,53 , and 88 percent.

The glass jars were right rectangular cylinders 13 in. long by 9 in. wide by 19 in. high, inside. The covers were sheet Lucite, $1 / 2$ in. thick. Hooks of Lucite rod were fused to the cover. Sulfur-free rubber tubing was cut lengthwise and sealed to the top edge of the jars with rubber cement. This rubber gasket was coated with Cello-Grease (Fisher Scientific Co.) to effect a seal between it and the cover. A weight of several pounds rested on the cover during the aging. The glass jars were kept together in a closed light-tight cabinet. The bottom of the cabinet was $4 \frac{1}{2} \mathrm{in}$. from the floor and there was free air space at least 3 in. thick surrounding the jars. The temperature in the cabinet was recorded automatically.

\subsection{Stability of Residual Thiosulfate in Silver-Free Microfilm}

Samples of microfilm were cut 10 in. in length and, without exposure, were developed, stopped, and fixed. After fixation, they were washed $1 \frac{1}{2}, 2$, or $3 \mathrm{~min}$ ai $25^{\circ} \mathrm{C}$ to obtain different concentrations of residual thiosulfate. Samples containing 3 to $23 \mu \mathrm{g}$ of thiosulfate per square inch were obtained by this procedure. The thiosulfate concentration was determined in six samples in each run and two of these were placed in each of the three glass jars having, respectively 14,53 , and 88 -percent relative humidity. The thiosulfate concentration was measured on 1 in. $^{2}$ of each sample at selected time intervals during 9 months. Table 1 gives the tabulated results of five runs. The two samples in each jar generally had the 
TABLE 1.-Effect of relative humidity on the concentration of thiosulfate in clear or silver-free processed microfilm during aging at room temperature $\left(20-30{ }^{\circ} \mathrm{C}\right)$ washed at $25^{\circ} \mathrm{C}$

[Runs 1,2 , and 3 were fixed in a silver-free bath; run 4 in a bath containing $4 \mathrm{~g}$ of silver per liter; and run 5 in a bath containing $8 \mathrm{~g}$ of silver per liter.]

\begin{tabular}{|c|c|c|c|c|c|c|c|}
\hline $\begin{array}{l}\text { Relative } \\
\text { humidity }\end{array}$ & Sample & \multicolumn{6}{|c|}{ Thiosulfate, $\mu \mathrm{g} / \mathrm{in} .^{2}$} \\
\hline \multicolumn{8}{|c|}{ Run 1 , washed 2 min } \\
\hline & & \multicolumn{6}{|c|}{ Time after processing, days } \\
\hline & & 0 & 14 & 28 & 83 & 149 & 269 \\
\hline $\begin{array}{l}\% \\
14 \\
53 \\
88\end{array}$ & $\begin{array}{l}\mathrm{a} \\
\mathrm{b} \\
\mathrm{c}\end{array}$ & $\begin{array}{l}3 \\
3 \\
3\end{array}$ & $\begin{array}{l}3 \\
3 \\
3\end{array}$ & $\begin{array}{l}3 \\
3 \\
3\end{array}$ & $\begin{array}{l}2 \\
2 \\
1\end{array}$ & $\begin{array}{l}2 \\
1 \\
0\end{array}$ & $\begin{array}{l}2 \\
1\end{array}$ \\
\hline \multicolumn{8}{|c|}{ Run 2 , washed $1 \frac{1}{2} \min$} \\
\hline & & \multicolumn{6}{|c|}{ Time after processing, days } \\
\hline & & 0 & 14 & 27 & 71 & 180 & 273 \\
\hline $\begin{array}{l}14 \\
53\end{array}$ & $\begin{array}{l}\mathrm{a} \\
\mathrm{b}\end{array}$ & $\begin{array}{l}8 \\
8\end{array}$ & $\begin{array}{l}8 \\
8\end{array}$ & $\begin{array}{l}8 \\
8\end{array}$ & $\begin{array}{l}8 \\
8\end{array}$ & $\begin{array}{l}8 \\
6\end{array}$ & $\begin{array}{l}8 \\
5\end{array}$ \\
\hline 88 & $\mathrm{c}$ & 8 & 8 & 7 & 6 & 4 & 3 \\
\hline
\end{tabular}

Run 3 , washed $1 \frac{1}{2}$ min

\begin{tabular}{l|r|r|r|r|r|r|r}
\hline & & \multicolumn{6}{|c}{ Time after processing, days } \\
\cline { 3 - 7 } & & 0 & 14 & 28 & 83 & 149 & 269 \\
\hline & & & & & & \\
14 & a & 10 & 10 & 10 & 10 & 10 & 10 \\
83 & b & 10 & 10 & 10 & 7 & 7 & 6 \\
88 & c & 10 & 9 & 8 & 5 & 4 & 2 \\
\hline
\end{tabular}

Run 4, washed 3 min

\begin{tabular}{l|r|r|r|r|r|r|r}
\hline & & \multicolumn{6}{|c}{ Time after processing, days } \\
\cline { 3 - 8 } & & 0 & 14 & 37 & 65 & 181 & 274 \\
\hline & & & & & & & \\
14 & a & 10 & 10 & 10 & 10 & 10 & 10 \\
53 & b & 10 & 10 & 10 & 10 & 9 & 9 \\
88 & c & 10 & 9 & 8 & 7 & 5 & 3 \\
\hline
\end{tabular}

Run 5, washed 3 min

\begin{tabular}{l|r|r|r|r|r|r|r}
\hline & & \multicolumn{5}{|c}{ Time after processing, days } \\
\cline { 3 - 7 } & & 0 & 27 & 50 & 185 & 279 & \\
\hline & & & & & & & - \\
53 & a & 23 & 23 & 23 & 23 & 23 & \\
88 & $\mathrm{~b}$ & 23 & 23 & 23 & 23 & 23 & 2 \\
& $\mathrm{c}$ & 23 & 18 & 15 & 5 & 2 & \\
\hline
\end{tabular}

same thiosulfate concentration with an occasional difference of $1 \mu \mathrm{g}$. The average value is reported in the table. The residual thiosulfate in silver-free processed microfilm was stable for 9 months at 14percent relative humidity. A slight amount of decomposition was found in the higher thiosulfate concentrations after only 2 weeks at 88 -percent relative humidity. Therefore, if tests are to be made on clear microfilm, they should be made within 2 weeks after processing if the samples are stored at about 90-percent relative humidity and within 2 months if they are stored at about 50-percent. When the samples were fixed in baths containing 4 and $8 \mathrm{~g}$ of silver per liter, respectively (runs 4 and 5 in table 1), the presence of this rather large amount of silver thiosulfate complex in the fixing bath did not materially affect the rate of decomposition of thiosulfate in the silver-free area of microfilm. In some runs, two samples were stored in a desiccator over anhydrous calcium sulfate and these always retained the same thiosulfate concentration as the two samples kept at 14-percent relative humidity.

\subsection{Stability of Residual Thiosulfate for Different Image Densities}

Step tablets of one microfilm were washed until the clear area ceased to give a positive test for thiosulfate. The densities of one step tablet in each

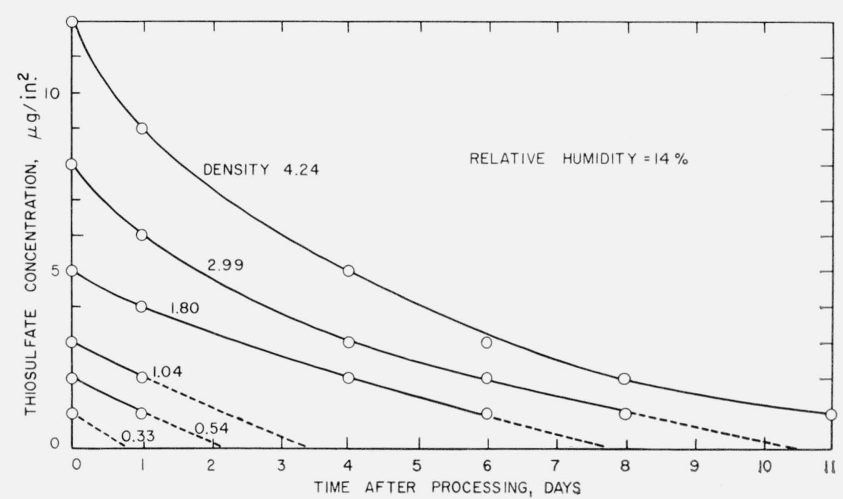

Figure 4. Decrease of thiosulfate concentration in different image densities during aging at 14-percent relative humidity and room temperature $\left(26\right.$ to $28{ }^{\circ} \mathrm{C}$ ) for microfilm $A$. The image densities are noted on the curves.

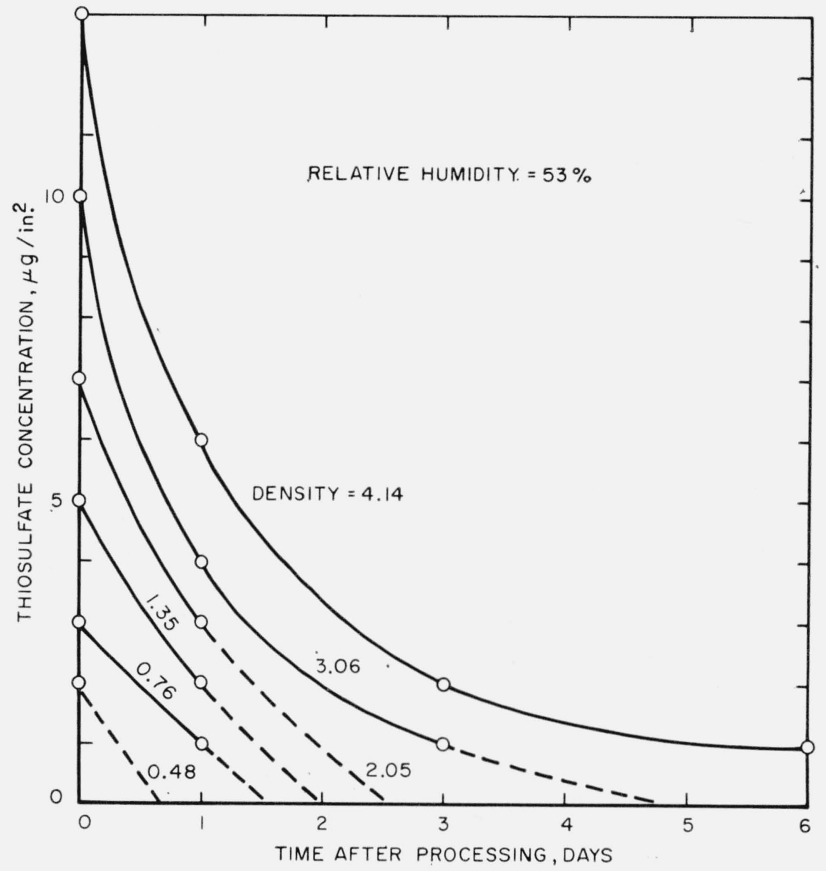

FIgure 5. Decrease of thiosulfate concentration in different image densities during aging at 53-percent relative humidity and room temperature $\left(29\right.$ to $\left.30{ }^{\circ} \mathrm{C}\right)$ for microfilm $A$.

The image densities are noted on the curves: 
run were measured and a square inch of film from each step of two tablets was analyzed for its thiosulfate content. The remaining samples were hung in one of the constant-humidity jars. At selected time intervals, the thiosulfate concentration was determined for each image density in one step tablet. The thiosulfate concentration versus time for each image density is shown in figure 4, for aging at 14-percent relative humidity; figure 5, for 53-percent; and figure 6 , for 88-percent. The concentration of thiosulfate in most of the silver densities became zero during the test and the curves are extrapolated (dashed line) to zero concentration at an estimated time when the thiosulfate test would be negative. This was also done in figure 3 . Figures 4,5 , and 6 show that the thiosulfate is unstable in the presence of silver and that the rate of reaction increases as the relative humidity increases. The rate of reaction was very high at the outset but diminished with time. In the highest image density no thiosulfate remained after 3 days at 88 -percent relative humidity, and only $1 \mu \mathrm{g}$ remained after 6 days at 53-percent, and 11 days at 14 -percent. Figure 6 shows that within $6 \mathrm{hr}$ at 88 -percent relative humidity there is an appreciable decrease in the thiosulfate concentration.

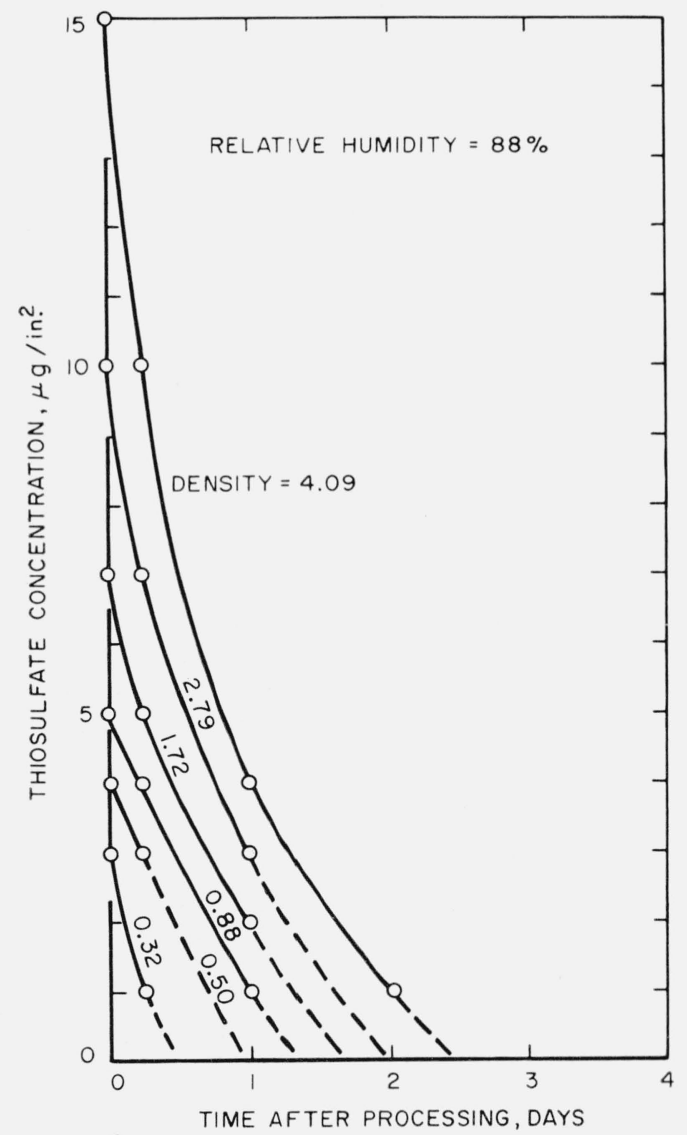

FIGURE 6. Decrease of thiosulfate concentration in different image densities during aging at 88-percent relative humidity and room temperature $\left(27-28{ }^{\circ} \mathrm{C}\right)$ for microfilm $A$.

The image densities are noted on the curves.
For this reason the first thiosulfate determination for each run was made within an hour after processing.

Table 2 gives the thiosulfate concentration for step tablets with high initial concentrations of residual thiosulfate after 1 to 90 days at 88-percent relative humidity. The step tablets were washed $2 \frac{1}{2}$ min at $6{ }^{\circ} \mathrm{C}$ to obtain these high thiosulfate concentrations. In another run, step tablets from the same kind of microfilm used to obtain the data in table 2 were fixed in a bath containing $8 \mathrm{~g}$ of silver per liter and essentially the same results were obtained as those shown in table 2. This indicates that the stability of thiosulfate is not greatly affected by the silver thiosulfate complex formed during fixing in the presence of silver. Table 2 shows that the reaction of the thiosulfate with the image silver was faster in the higher densities where there was more available silver for sulfiding. The thiosulfate in the low image densities reacted if aged long enough.

TABLE 2. Thiosulfate concentration in different image densities during aging at 88 -percent relative humidity and room temperature $\left(22-27{ }^{\circ} \mathrm{C}\right)$

\begin{tabular}{c|r|r|r|r|r|r}
\hline \hline & \multicolumn{5}{|c}{ Thiosulfate Concentration, $\mu \mathrm{g} / \mathrm{in.}^{2}$} \\
\cline { 2 - 6 } Density & \multicolumn{5}{|c}{ Time after processing, days } \\
\cline { 2 - 6 } & 0 & 1 & 9 & 21 & 59 & 90 \\
\hline & & & & & & \\
\hline & & & & & \\
\hline 0.00 & 27 & 25 & 25 & 23 & 13 & 10 \\
.43 & 37 & 33 & 33 & 30 & 10 & 5 \\
.68 & 40 & 35 & 33 & 27 & 4 & 1 \\
1.17 & 45 & 40 & 35 & 22 & 0 & 0 \\
2.06 & 50 & 40 & 27 & 0 & 0 & 0 \\
3.16 & 55 & 43 & 10 & 0 & 0 & 0 \\
4.39 & 63 & 43 & 2 & 0 & 0 & 0 \\
& & & & & & \\
\hline
\end{tabular}

The above experimental results show that the test for residual thiosulfate in image silver of processed microfilm should be made within an hour after processing. Even at 14-percent relative humidity the thiosulfate reacts slowly with the silver in the image.

\section{Formation of Silver Sulfide in the Image at 88-Percent Relative Humidity}

Residual thiosulfate in the processed film reacted with the image silver to form silver sulfide. Any thionates, if present, would also react with the image silver to form silver sulfide. The reaction was slow at low humidity but quite rapid at high humidity and continued until the silver or the thiosulfate was exhausted. The amount of sulfiding of the image silver during aging was determined in terms of optical transmission density of the silver which had been sulfided. The image silver remaining after aging was removed by a bleach, leaving the silver sulfide image or residue which was then reduced to silver. The process was carried on in daylight but not in direct sunlight. 
The step tablets were treated $5 \mathrm{~min}$ in a dichromate bleach bath (see appendix 9.2), washed $10 \mathrm{~min}$ in tap water at $25{ }^{\circ} \mathrm{C}$, treated 3 min in a clearing bath, fixed $3 \mathrm{~min}$, and washed $10 \mathrm{~min}$ in running tap water. After the step tablets having an image of silver sulfide were dried, they were treated 2 to $3 \mathrm{~min}$ at $25^{\circ} \mathrm{C}$ in a permanganate bleach bath (see appendix 9.3 ), rinsed 10 sec in running tap water, treated 2 to $3 \mathrm{~min}$ in a clearing bath at $15^{\circ} \mathrm{C}$, washed $10 \mathrm{~min}$ in running tap water at $15{ }^{\circ} \mathrm{C}$, shaken to remove surface water, and hung to dry in the dark. The step tablets were then exposed for 10 min to a $100-\mathrm{w}$ tungsten lamp at a distance of 12 in., developed 5 min at $20^{\circ} \mathrm{C}$, treated $1 \mathrm{~min}$ in the stop bath at $15^{\circ} \mathrm{C}$, washed $5 \mathrm{~min}$ in running tap water at $15^{\circ} \mathrm{C}$, shaken to remove excess water, and hung to dry. The step tablets then had an image of silver obtained by the reduction of the silver sulfide.

Eight step tablets were used in each run. The image densities were measured on one step tablet and the thiosulfate concentration was determined for each density of two tablets after processing and one tablet after aging. After processing, two tablets were treated in the thiosulfate eliminator described in appendix 9.1 to determine the amount of sulfiding of the silver image during fixation. Two tablets were aged at 88-percent relative humidity and treated in the thiosulfate eliminator. The two tablets that had been treated in the eliminator after processing and the two that had been aged and treated in the eliminator were bleached at the same time to obtain the silver sulfide image which was then reduced to the silver image.

Eight step tablets of one microfilm were fixed and washed $3 \mathrm{~min}$ at $25^{\circ} \mathrm{C}$ to obtain low thiosulfate concentrations in the image densities. The results are shown in table 3 . Two of the tablets were aged 6 days, at the end of which time all of the residual thiosulfate had disappeared. There was an increase in the amount of silver sulfided for all densities. The density of silver sulfided during aging is not shown directly in table 3 but may be obtained by subtracting the density of the silver sulfided during fixation from the density of silver sulfided during fixation and aging.

TABLE 3. Density of the silver sulfided during fixation and by reaction with residual thiosulfate in the processed microfilm during aging at 88-percent relative humidity at room temperature

\begin{tabular}{|c|c|c|c|c|}
\hline \multirow[b]{2}{*}{$\begin{array}{l}\text { Original } \\
\text { density }\end{array}$} & \multicolumn{2}{|c|}{$\begin{array}{l}\text { Residual thiosulfate, } \\
\mu \mathrm{g} / \text { in. }^{2}\end{array}$} & \multicolumn{2}{|c|}{$\begin{array}{l}\text { Density of silver image obtained } \\
\text { by bleaching and reducing the } \\
\text { silver sulfide image }\end{array}$} \\
\hline & $\begin{array}{c}\text { After } \\
\text { processing }\end{array}$ & $\begin{array}{l}\text { After } \\
\text { aging }\end{array}$ & $\begin{array}{l}\text { Silver } \\
\text { sulfided } \\
\text { during } \\
\text { fixation }\end{array}$ & $\begin{array}{c}\text { Silver sulfided during } \\
\text { fixation }+ \text { silver sulfided } \\
\text { by reaction with } \\
\text { thiosulfate during } 6 \\
\text { days at } 88 \% \\
\text { rh }\left(25-26^{\circ} \mathrm{C}\right)\end{array}$ \\
\hline $\begin{array}{r}0.00 \\
.32 \\
.54 \\
.98 \\
1.88 \\
3.00 \\
4.43\end{array}$ & $\begin{array}{r}0 \\
2 \\
3 \\
5 \\
7 \\
10 \\
15\end{array}$ & $\begin{array}{l}0 \\
0 \\
0 \\
0 \\
0 \\
0 \\
0\end{array}$ & $\begin{array}{l}0.00 \\
.01 \\
.02 \\
.05 \\
.09 \\
.15 \\
.22\end{array}$ & $\begin{array}{l}0.00 \\
.02 \\
.04 \\
.07 \\
.14 \\
.21 \\
.30\end{array}$ \\
\hline
\end{tabular}

Eight step tablets of one microfilm were fixed and washed $3 \mathrm{~min}$ at $3.5{ }^{\circ} \mathrm{C}$ to obtain high thiosulfate concentrations in the image densities. Two tablets were aged 27 days. The results are shown in table 4. Some of the thiosulfate remained in the low densities after 27 days but none was left in the high densities. The data in tables 3 and 4 show that the residual thiosulfate in processed microfilm reacts readily with the image silver to form silver sulfide at 88-percent relative humidity.

TABLE 4. Density of the silver sulfided during fixation and by reaction with residual thiosulfate in the processed microfilm during aging at 88-percent relative humidity at room temperature

\begin{tabular}{|c|c|c|c|c|}
\hline \multirow[b]{2}{*}{$\begin{array}{l}\text { Original } \\
\text { densit y }\end{array}$} & \multicolumn{2}{|c|}{$\begin{array}{c}\text { Residual thiosulfate, } \\
\mu \mathrm{g} / \text { in. }^{2}\end{array}$} & \multicolumn{2}{|c|}{$\begin{array}{l}\text { Density of silver image obtained } \\
\text { by bleaching and reducing the } \\
\text { silver sulfide image }\end{array}$} \\
\hline & $\begin{array}{l}\text { After } \\
\text { processing }\end{array}$ & $\begin{array}{l}\text { After } \\
\text { aging }\end{array}$ & $\begin{array}{l}\text { Silver } \\
\text { sulfided } \\
\text { during } \\
\text { fixation }\end{array}$ & $\begin{array}{c}\text { Silver sulfided during } \\
\text { fixation + silver sulfided } \\
\text { by reaction with } \\
\text { thiosulfate during } 27 \\
\text { days at } 88 \% \\
\text { rh }\left(23-27^{\circ} \mathrm{C}\right)\end{array}$ \\
\hline $\begin{array}{r}0.00 \\
.38 \\
.62 \\
1.06 \\
1.95 \\
3.08 \\
4.46\end{array}$ & $\begin{array}{l}35 \\
45 \\
47 \\
50 \\
55 \\
60 \\
70\end{array}$ & $\begin{array}{r}15 \\
15 \\
10 \\
3 \\
0 \\
0 \\
0\end{array}$ & $\begin{array}{l}0.00 \\
.01 \\
.02 \\
.05 \\
.10 \\
.15 \\
.20\end{array}$ & $\begin{array}{l}0.00 \\
.08 \\
.12 \\
.22 \\
.33 \\
.39 \\
.46\end{array}$ \\
\hline
\end{tabular}

\section{Effect of the Silver Concentration in the Acid Fixing Bath on the Residual Thio- sulfate Concentration in Processed Microfilm}

Experiments were made to determine the effect of the silver concentration in the fixing bath on the retention of thiosulfate in microfilm during washing. The addition of silver to the fixing bath causes the formation of a silver thiosulfate complex, the presence of which makes it difficult to remove the thiosulfate by washing. The silver was added to the fixing bath in the form of silver bromide. Four step tablets were fixed at the same time, one each in four fixing baths containing different concentrations of silver, and were washed in the same pan for 10 min at $25^{\circ} \mathrm{C}$. The effect of the silver concentration in the fixing bath on the retention of thiosulfate during washing for different image densities is shown for one microfilm in figure 7 . The residual thiosulfate concentration in the microfilm during washing varied linearly with the silver concentration in the fixing bath for each image density.

\section{Total Elimination of Thiosulfate From Microfilm After Fixation}

Complete elimination of the thiosulfate is necessary for the determination of the amount of sulfiding of the silver image during fixation and aging. 


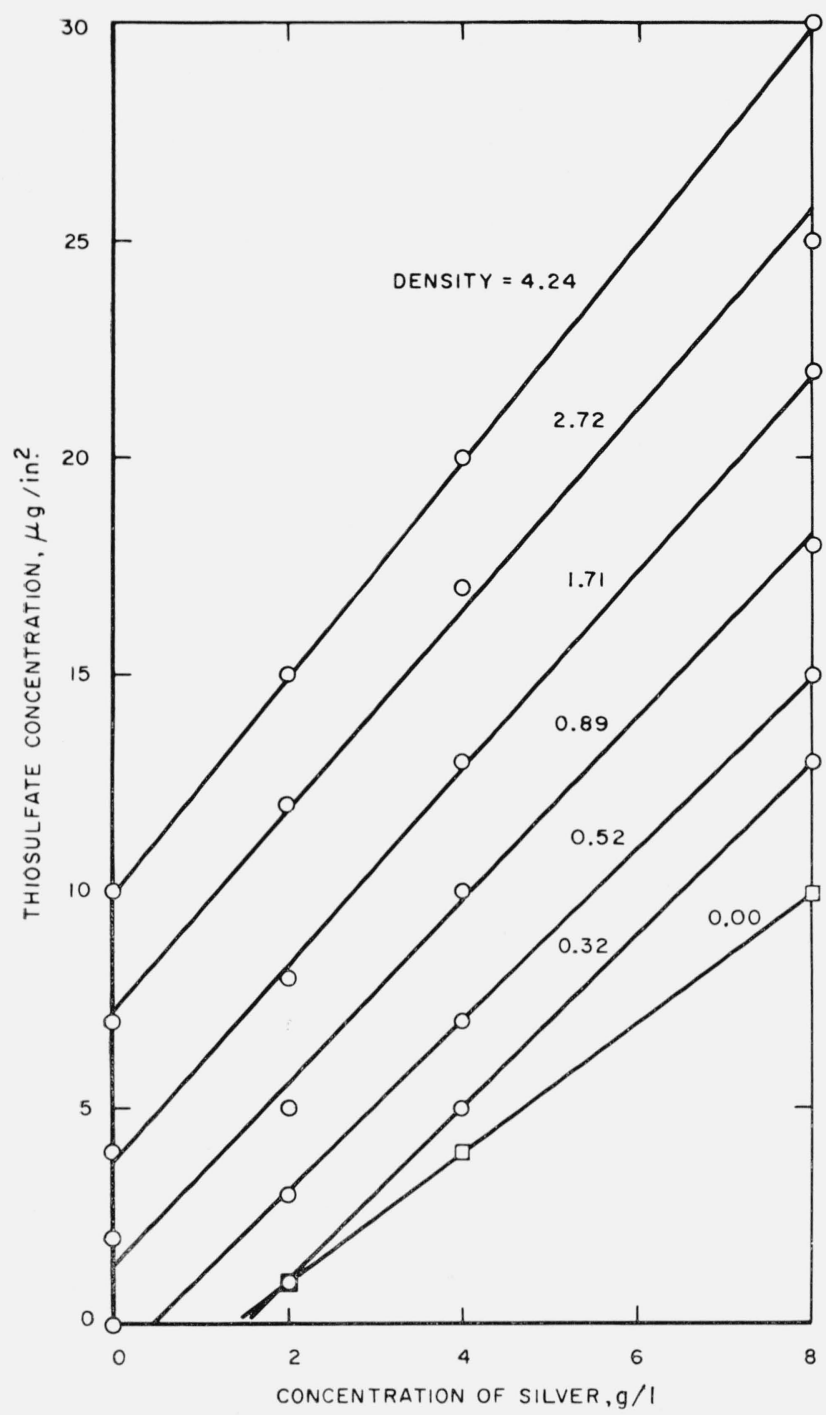

FIGURE 7. Effect of the silver concentration in the fixing bath on the concentration of residual thiosulfate for different image densities after a 10-min wash at $25^{\circ} \mathrm{C}$, on one microfilm.

A residual thiosulfate concentration of 2 or $3 \mu \mathrm{g} / \mathrm{in}^{2}$ will give a measurable increase in silver sulfide during aging as shown in table 3 for the low image densities. Washing for $1 \mathrm{hr}$ will not completely remove thiosulfate from the areas of high image density of most microfilms. Even after treatment in alkali solutions, tablets still contained traces of thiosulfate in these areas, and an investigation was made to find how the thiosulfate could be completely eliminated.

A hydrogen peroxide-ammonium hydroxide solution has been recommended for the removal of thiosulfate from photographic materials [7]. Step tablets were fixed and washed $3 \mathrm{~min}$, treated $10 \mathrm{~min}$ in the thiosulfate eliminator at $20^{\circ} \mathrm{C}$, and washed $15 \mathrm{~min}$ at $25^{\circ} \mathrm{C}$. The formula for the eliminator was as follows:
Hydrogen peroxide $(30 \%)$ $50 \mathrm{ml}$ Ammonium hydroxide (28\%) . . . . $10 \mathrm{ml}$ Water to make 1 liter

The image densities and residual thiosulfate concentrations are given in table 5 for fixation in a silver-free bath and a bath containing $8 \mathrm{~g}$ of silver per liter. The thiosulfate concentrations were about the same as those obtained when the microfilm was washed for $1 \mathrm{hr}$ in running tap water, as indicated in figure 3 . The concentrations of thiosulfate were slightly higher in the step tablet fixed in the bath containing silver, showing that more of the silver thiosulfate complex was retained in the emulsion. The hydrogen peroxide did not oxidize all of the thiosulfate bound in the silver thiosulfate complex in the high image densities.

TABIE 5. Thiosulfate concentration in different image densities after treatment in the hydrogen peroxide and ammonium hydroxide solution following fixation

\begin{tabular}{|c|c|c|c|}
\hline \multicolumn{2}{|c|}{ Silver-free fixing bath } & \multicolumn{2}{|c|}{$\begin{array}{c}\text { Fixing bath }+8 \mathrm{~g} \text { of silver } \\
\text { per liter }\end{array}$} \\
\hline Density & Thiosulfate & Density & Thiosulfate \\
\hline $\begin{array}{r}0.00 \\
.21 \\
.39 \\
.74 \\
1.58 \\
2.64 \\
4.36\end{array}$ & $\begin{array}{c}\mu g / i n .^{2} \\
0 \\
0 \\
0 \\
1 \\
2 \\
4 \\
7\end{array}$ & $\begin{array}{r}0.00 \\
.18 \\
.40 \\
.80 \\
1.72 \\
2.98 \\
4.74\end{array}$ & $\begin{array}{c}\mu g / \text { in } .^{2} \\
0 \\
0 \\
0 \\
2 \\
4 \\
7 \\
10\end{array}$ \\
\hline
\end{tabular}

It was found that the thiosulfate in the silver thiosulfate complex ion could be oxidized in solution by hydrogen peroxide in the presence of sodium chloride, potassium bromide, and potassium iodide. To demonstrate this, the following test solution was used, the chemicals being added in the order listed:

Water $400 \mathrm{ml}$

Silver nitrate, $\mathrm{AgNO}_{3}$ $0.5 \mathrm{~g}$

Ammonium hydroxide $(28 \%)$ $20 \mathrm{ml}$

Sodium thiosulfate, $\mathrm{Na}_{2} \mathrm{~S}_{2} \mathrm{O}_{3} \cdot 5 \mathrm{H}_{2} \mathrm{O}$ $0.2 \mathrm{~g}$

Hydrogen peroxide $(30 \%)$ $25 \mathrm{ml}$

Water to make $500 \mathrm{ml}$

A black precipitate of silver sulfide was formed when the above solution was acidified with concentrated nitric acid. The nitric acid decomposed the silver thiosulfate complex forming silver sulfide. However, when a sufficient concentration of the halide salts was added before acidification by nitric acid, no dark precipitate or brownish coloration resulted, showing that the thiosulfate had been released from the silver thiosulfate complex ion and oxidized by the peroxide. The halide salts were dissolved in $25 \mathrm{ml}$ of water and added to the above test solution. 
The following approximate amounts of the halide salts were found necessary to eliminate the thiosulfate silver complex ion:

\begin{tabular}{l} 
Sodium chloride \\
Potassium bromide \\
Potassium iodide $\ldots \ldots$ \\
\hline
\end{tabular}

The silver in the silver thiosulfate complex ion appears to react with the halide ion to form silver halide thereby releasing the thiosulfate anion according to the following equation:

$$
\mathrm{Ag}\left(\mathrm{S}_{2} \mathrm{O}_{3}\right)_{2}^{---}+\text {Halide ion } \rightarrow \text { AgHalide }+2 \mathrm{~S}_{2} \mathrm{O}_{3}^{--}
$$

The small amount of silver halide is soluble in the excess halide present. This is apparently how sodium chloride in sea water assists in removing thiosulfate from processed photographic materials after fixation. The effectiveness of the different halide ions in eliminating the silver thiosulfate complex ion increases as the solubility of their silver salts decreases.

Step tablets of microfilm having a high image density (about 4.5) were fixed in a bath containing $8 \mathrm{~g}$ of silver per liter, washed $3 \mathrm{~min}$ in running tap water at $25^{\circ} \mathrm{C}$, and treated for $10 \mathrm{~min}$ at $25^{\circ} \mathrm{C}$ in one of the following solutions: 6-percent sodium chloride, 3-percent potassium bromide, or 0.15percent potassium iodide, and were washed $15 \mathrm{~min}$ in running tap water at $25^{\circ} \mathrm{C}$. The thiosulfate was completely eliminated in all image densities by the solutions of potassium bromide and potassium iodide. The sodium chloride solution left $1 \mu \mathrm{g}$ of thiosulfate per square inch in an image density of 1.6 and $3 \mu \mathrm{g}$ in the highest image density of 4.5 , showing that sodium chloride does not remove the last traces of thiosulfate in the highest image densities.

A 0.15-percent solution of potassium iodide precipitated the silver in the silver thiosulfate complex ion as silver iodide in the emulsion. This released the thiosulfate which, in turn, was readily washed out of the emulsion. Any silver halide in the emulsion is reducible to silver. A sample of unexposed microfilm was developed, stopped, fixed in a bath containing $8 \mathrm{~g}$ of silver per liter, washed in tap water for $3 \mathrm{~min}$ at $25^{\circ} \mathrm{C}$, treated in a 0.15 percent solution of potassium iodide, and washed $15 \mathrm{~min}$ at $25^{\circ} \mathrm{C}$ in running tap water. For the reduction of the silver iodide to silver the sample was bleached in the permanganate bleach solution, cleared, dried, exposed to sunlight $30 \mathrm{~min}$, and developed. An image density of 0.07 was obtained, showing that the silver in the silver thiosulfate complex ion had been precipitated as silver iodide in the emulsion by the potassium iodide. The experiment above was repeated except that the sample of microfilm was treated in a 0.10 -percent potassium bromide solution but silver bromide could not be detected in the emulsion, evidently due to the greater solubility of silver bromide over that of silver iodide.

A 3-percent solution of potassium bromide and a 4.5-percent solution of potassium iodide eliminated the thiosulfate completely from the high image density areas of the microfilm. When the 4.5percent potassium iodide solution was used, no precipitated silver iodide could be detected in the clear area of the emulsion which may be explained by the "common ion" effect, i.e., there was a sufficient concentration of potassium iodide to keep the silver iodide in solution as a complex of silver iodide and potassium iodide.

\section{Summary}

The residual thiosulfate concentration in processed microfilm was found to vary linearly with the image density up to a density of about 2 and then to level off.

The residual thiosulfate in the clear or silver-free area of processed microfilm was stable for at least 9 months at 14-percent relative humidity and room temperature but, in samples containing about $10 \mu \mathrm{g} /$ in. $^{2}$, it began to decompose after about 2 weeks at 88 -percent relative humidity. The residual thiosulfate reacted with the silver in the image to form silver sulfide and the rate of sulfiding of the silver in the image increased as the relative humidity increased. The sulfiding of the silver in the high image densities continued until the thiosulfate was exhausted. In very low image densities the silver was exhausted when the thiosulfate concentration was high.

The thiosulfate test for residual thiosulfate in processed microfilm should be made on a clear or silver-free area of the film. The test should be made within two weeks after processing if the sample is stored at a relative humidity as high as 90 percent. However, if the film is stored at a relative humidity of 14 percent or lower, the residual thiosulfate test on the clear area of microfilm is valid for at least 9 months after processing. Samples of silvor-free microfilm can be stored in a desiccator if delay in making the thiosulfate test cannot be avoided. The residual thiosulfate test on microfilm having high image densities should be made within $1 \mathrm{hr}$ after processing.

In the case of one kind of microfilm involved in this study the thiosulfate was removed rapidly and almost completely in the high silver image densities during washing and the sulfiding of the image silver was much lower than that of the other four microfilms investigated. When potassium iodide was added to the fixing bath the thiosulfate in the other four microfilms also washed out rapidly in the high density silver image areas and the amount of the silver image sulfided was negligible. There appears to be a relationship between the sulfiding of the 
image silver during fixation and the retention of the thiosulfate during washing.

The hydrogen peroxide-ammonium hydroxide thiosulfate eliminator did not remove all of the silver thiosulfate complex ion unless potassium bromide was added to decompose it. The chloride, bromide, and iodide ions in a thiosulfate eliminator decomposed the silver thiosulfate complex ion, releasing the thiosulfate ion which was then readily removed by washing or oxidation. A 3-percent solution of potassium bromide or a $4 \frac{1}{2}$-percent solution of potassium iodide eliminated thiosulfate from microfilm which had been fixed in a bath containing $8 \mathrm{~g}$ of silver per liter.

\section{Appendix}

\subsection{Formulas for Developing and Fixing the Silver Image in the Microfilm}

\section{Developer}

Monomethyl $p$-aminophenol sulfate

Sodium sulfite, anhydrous

$3.1 \mathrm{~g}$.

Hydroquinone

Sodium carbonate, anhydrous

$45.0 \mathrm{~g}$.

Potassium bromide. $12.0 \mathrm{~g}$.

Water to make

$67.5 \mathrm{~g}$.

$1.9 \mathrm{~g}$.

Dilute 1 to 1 before use.

1 liter.

\section{Stop Bath}

Acetic acid, glacial $12 \mathrm{ml}$.

Water to make 1 liter.

\section{Acid Fixing Bath}

Sodium thiosulfate, $\mathrm{Na}_{2} \mathrm{~S}_{2} \mathrm{O}_{3} \cdot 5 \mathrm{H}_{2} \mathrm{O}$ $240.0 \mathrm{~g}$.

Sodium sulfite, anhydrous

Acetic acid $(28 \%)$. $15.0 \mathrm{~g}$.

Boric acid $48 \mathrm{ml}$.

Potassium aluminum sulfate, $\mathrm{KAl}\left(\mathrm{SO}_{4}\right)_{2}$. $12 \mathrm{H}_{2} \mathrm{O}$ $7.5 \mathrm{~g}$.

Wate. to make $15.0 \mathrm{~g}$. 1 liter.

Acid Fixing Bath containing $8 \mathrm{~g}$ of silver per liter

Above acid fixing bath 1 liter.

Silver bromide $13.9 \mathrm{~g}$.

\section{Thiosulfate Eliminator}

Water

Hydrogen peroxide $(30 \%)$

$300 \mathrm{ml}$.

Ammonium hydroxide $(28 \%)$ $50 \mathrm{ml}$.

Potassium bromide

$10 \mathrm{ml}$.

Water to make

$1.0 \mathrm{~g}$.

1 liter.

After fixation or aging the sample of film was washed $3 \mathrm{~min}$ in running tap water, treated $10 \mathrm{~min}$ in the above solution, bathed for $2 \mathrm{~min}$ in a 1-percent solution of sodium sulfite, and washed $15 \mathrm{~min}$ in running tap water.
9.2. Formulas for the Bleaching Process in Which the Silver of the Photographic Image Is Removed and the Silver Sulfide Is Left as a Residue in the Emulsion Layer

\section{Bleach Bath}

Potassium dichromate $5.0 \mathrm{~g}$.

Sulfuric acid $(95 \%)$ $5.0 \mathrm{ml}$

Water to make. 1 liter.

\section{Clearing Bath}

Sodium sulfite, anhydrous $50.0 \mathrm{~g}$. Sodium hydroxide $1.0 \mathrm{~g}$.

Water to make. 1 liter.

\section{Fixing Bath}

Sodium thiosulfate, $\mathrm{Na}_{2} \mathrm{~S}_{2} \mathrm{O}_{3} \cdot 5 \mathrm{H}_{2} \mathrm{O}$ $240 \mathrm{~g}$.

Sodium carbonate, anhydrous _. _ _ _ _ 5 g.

Water to make. 1 liter.

\subsection{Formulas for Reducing the Silver Sulfide Residue} in the Gelatin Layer to Silver

\section{Bleach Bath}

Potassium permanganate

Sodium chloride

Acetic acid, glacial $5.0 \mathrm{~g}$.

Water to make $10.0 \mathrm{~g}$. $50 \mathrm{ml}$. 1 liter.

\section{Clearing Bath}

Sodium bisulfite

Potassium bromide $50.0 \mathrm{~g}$. Water to make. $12.0 \mathrm{~g}$. 1 liter.

\section{Developer}

2,4-Diaminophenol Dihydrochloride ___ _ $5.0 \mathrm{~g}$.

Sodium sulfite, anhydrous _ _. _ _ _ _ $30.0 \mathrm{~g}$.

Water to make. 1 liter.

\section{Stop Bath}

Same as used in section 9.1

\subsection{Quality of the Chemicals Used for the Formulas Listed in This Appendix}

All of the solutions were made up with distilled water. The following chemicals were of reagent quality meeting ACS specifications: ammonium hydroxide, acetic acid, barium chloride, boric acid, potassium bromide, potassium dichromate, potassium permanganate, sodium chloride, sodium carbonate, sodium hydroxide, sodium sulfite, and sulfuric acid. Lithium chloride, hydrogen peroxide, and sodium dichromate were of reagent grade. The monomethyl $p$-aminophenol sulfate, hydroquinone, potassium. 
aluminum sulfate, sodium thiosulfate, and sodium bisulfite conformed to American Standard Specifications for Photographic Grade Chemicals. The silver bromide was Fisher, purified. The 2,4-Diaminophenol Dihydrochloride was Eastman Kodak Cat. No. P-614.

\section{References}

[1] E. P. Przybylowic, C. W. Zuehlke, and A. E. Ballard, An evaluation of the Crabtree-Ross procedure for residual hypo in processed film, Phot. Sci. Eng. 2, No. 3,148 (1958).

[2] American Standard Specifications for Photographic Films for Permanent Records, PH1.28-1957 (American Standards Association, Inc., 10 East 40th St., New York 16, N. Y.).
[3] American Standard Diffuse Transmission Density, PH2.19-1959 (American Standards Association, Inc., 10 East 40th St., New York 16, N. Y.).

[4] American Standard Method for Determining the Thiosulfate Content of Processed Black-and-White Photographic Film and Plates, PH4.8-1958 (American Standards Association, Inc., 10 East 40th St., New York 16, N. Y.).

[5] Peter Scott, The permanence of photographic silver film with special emphasis on microfilm, Proceedings of the National Microfilm Association, p. 179-202, 1958 (National Microfilm Association, Annapolis, Md.).

[6] C. I. Pope, Formation of silver sulfide in the photographic image during fixation, .J. Research NBS 64C, 65 (1960).

[7] J. I. Crabtree, G. T. Eaton, and L. E. Muehler, The elimination of hypo from photographic images, Am. Phot. 35, No. 4, 272 (1941).

(Paper 67C1-115) 